\title{
Waste source owners in the industrial solid waste management in Vietnam
}

\author{
Minh Duc Tran ${ }^{1, *}$ \\ ${ }^{1}$ Graduate Academy of Social Sciences, Nguyen Trai Street, No. 477, Thanh Xuan District, Ha Noi, \\ 10000, Vietnam
}

\begin{abstract}
Management of industrial solid waste is predicted becoming more complex as Vietnam develops rapidly, strives to become an industrialised country towards modernisation. In order to manage efectivelly industrial solid waste, there must be the participation of many actors in the waste management cycle, among them, it is necessary to mention the owner of industrial solid waste. Responsibilities of the owners of the industrialised solid waste that emitted to the environment are an issue that needs to be clarified in the waste management. Therefore, this paper concentrates on analysing the current laws in Vietnam defining the responsibilities the waste source owners and the mechanism to implement these responsibilities in the management of industrial solid waste. The writing figures out some limitations and inadequacies in defining responsibilities of the owners of the industrial solid waste sources. Then, it proposes a number of solutions that enhances responsibilities of the waste source owners in the industrial solid waste management. They are: 1/ Need more specific regulations on the responsibilities of the owners of the waste sources in classification of waste; 2/ Improve regulations on the market of waste goods; 3/ Supplementing regulations on specialised personnel at facilities generating industrial solid waste; 4/ Strengthen inspection, examination and supervision on the waste source owers; 5/ Improve the law on the system of economic intrusments to regulate acts of the owners of waste sources; 6 / Mobilise community responsibilities participating and promote socialisation in industrial solid waste management.
\end{abstract}

\section{Introduction}

In theoretical perspective, the term "responsibility" not only is a duty to deal with or take care of something, but also includes taking the onus of the results of such actions. "Responsibility" expresses the ability of an individual or an organisation that acknowledge their actions in doing something; at the same time, it implies an obligation to explain, report, provide information, and justify such matters and their consequences, as well as being willing to be assessed, judged, or even punished legally and morally for those consequences [2]. Owners of waste sources are individuals, organisations that own or operate facilities generating waste. They must have certain responsibilities in managing waste generated by themselves for the environment. Therefore, the study of the

\footnotetext{
*Corresponding author: tranminhducdanang@gmail.com
} 
responsibility of the owners of waste sources in industrial solid waste management is to discuss must-do and allowed activities of the owners of waste sources and their responsible actions for the results.

The political report at the $12^{\text {th }}$ National Party Congress affirmed the overall objective and mission of developing Vietnam in the period 2016-2021 as "Rapid, sustainable development, striving to build our country to become basically an industrialised country towards modernisation soon". The contribution of industry and construction sectors accounted for 33.3\% of Vietnam's GDP in 2016, and will keep increasing in the near future. Production, business and service sectors in urban areas, the increasingly expanding and developing industrial zones have contributed positively to the country's development, on the other hand that has generated a large amount of waste [1]. Industrial solid waste includes the amount of solid waste generated from industrial parks and production facilities located outside industrial parks. The number of independent production facilities is scattered and very large in Vietnam. However, the amount of the solid waste has not been adequately statistical, especially from small-scale production facilities, which are interspersed with residential areas. The industrial solid waste generated from industries such as paper production, coal-fired thermal power industry, chemicals, fertilisers... has specific characteristics of each industry and has increased significantly over the past time. According to the statistics of the Vietnam Department of Waste Management and Environment Improvement, the amount of ordinary solid waste generated from industrial production activities is estimated at 25 million tons/year [1].

The growth rate of solid waste is about $10 \%$ per year and will continue to increase significantly in the coming time in both quantity and toxic level. Currently, there are many facilities causing serious environmental pollution that have not been completely handled. Many industrial facilities located in residential areas are slowly relocated. Many projects and production facilities that are likely to cause environmental pollution have not been seriously dealt with; most industrial clusters do not have adequate infrastructure for industrial solid waste management; most trade villages still causing environmental pollution have not been unresolved, leading to the environmental pollution in some trade villages is quite serious. Some industries have high recycling potential, but the management of waste has revealed many limitations. For example, the paper industry, the proportion of used paper recalled compared to total paper consumption is only about $25 \%$. If the collect rate of the used paper in Vietnam can be doubled, Vietnam does not need to import scrap paper and can partially replace other sources of raw materials such as wood, jute... [2 ].

With the increasing challenges in industrial solid waste management in Vietnam at present and in the future, the study to improve the regulations of responsibilities of the parties in a relationship of the solid waste management is needed, especially the responsibility of the owners of the waste sources in strengthening the application of measures on saving resources and energy; using natural resources, renewable energy and environmentally friendly products, raw materials and energy; cleaner production and the responsibility to use other measures to prevent and reduce the generation of the industrial solid waste; implementing thoroughly the principle of "polluters pay" in defining responsibilities of the parties related to the industrial solid waste management in order to regulate behaviours in an environmentally friendly manner, raising the responsibilities and attracting the participation of organisations and individuals in environmental protection.

\section{Materials and research methods}

The author uses analytical methods to analyse the legal provisions on the responsibility of the waste source owner in the management of industrial solid waste in Vietnam; statistical methods to synthesise data on industrial solid waste in Vietnam; analytical and synthesis 
methods to make assessments on the process of applying the law on the responsibility of these owner of the waste sources in the management of industrial solid waste. The analysis of laws and researching articles, reports, data related to the industrial solid waste management are the basis to make recommendations that contribute to improving the responsibility of the owners of waste sources in the management of the industrial solid waste in Vietnam currently.

\section{Research results}

\subsection{Current situation on the responsibility of owners of waste sources in the industrial solid waste management}

The responsibility of the waste source owner in the industrial solid waste management is greatly influenced by an approach to industrial solid waste. According to the traditional approach in Vietnam, all types of waste (materials removed from human activities) are managed by a common process of minimising, classifying, collecting, treating and destruction; waste is not recognised from an economic perspective and seems to become a social burden because of environmental issues and the cost to deal with them. Hence, the responsibility of the owner of the industrial solid waste is only focus on reducing and treating, destroying waste. However, the natural resources are increasingly scarce, the price of raw materials is increasing, along with the raising awareness of environmental protection, approaching the concept of a circulating economy in management of waste for sustainable development. Therefore, the waste is currently approached in a perspective that waste is considered as a resource. A good waste management not only is safe collection, treatment and burying, but also needs to consider the economic benefits of each type of waste to reuse, recycle and recover energy for other purposes than just waste. The law on waste management in Vietnam currently has regulations to encourage the recycling, reusing, and recovering of waste energy. Thus, the provisions on responsibilities of the waste source owner in the management of the industrial solid waste are also different from before.

According to Article 3 in the Document consolidating decrees on waste and scrap management of the Ministry of Natural Resources and Environment issued on October $25^{\text {th }}$, 2019, solid waste is solid or thick waste (also called mud waste) that is discharged from production, business, services, daily activities or other activities. Industrial solid waste means solid waste generated from production, business and service activities, including hazardous and ordinary industrial solid waste. Hazardous waste contains toxic, radioactive, infectious, inflammable, explosive, corrosive, poisoning or other hazardous properties; ordinary solid waste is the waste that is not on hazardous waste list of Vietnam or on the list of hazardous wastes but has hazardous elements below the dangerous threshold.

The current laws of Vietnam are approaching a cycle management. This includes a process of prevention, mitigation, monitoring, classifiction, collection, transportation, recycling and handling waste in the industrial solid waste management. Therefore, the law based on the nature of the industrial solid waste is ordinary or hazardous and based on the waste management process to define the responsibility for the owners of the industrial solid waste. Specifically, according to the Decree on waste and scrap management in 2019, the responsibilities of the waste source owner in the management of the industrial solid waste are as follows:

Firstly, the responsibility of the owner of waste sources to discern, classify, and store the industrial solid wastes: In principle, ordinary industrial solid wastes must be discerned and segregated separately from hazardous wastes. If it cannot classify, it must be managed 
in accordance with hazardous waste regulations. Due to the characteristics of each type of waste, the provisions of responsibilities of the owner of waste sources on the discernment, classification and storage of the hazardous industrial solid wastes are also stricter than those of the ordinary solid waste, specifically:

- For the ordinary industrial solid waste: The discernment, classification and storage of ordinary industrial solid waste must meet technical requirements and management processes prescribed by Vietnamese law. As the current law considers waste to be a resource, this regulates the classification of common solid waste into the following three groups: i) The group of common industrial solid wastes is reused and recycled as raw materials for the production process; ii) The group of solid waste used in the production of construction materials and ground leveling; iii) The group of common industrial solid wastes must be treated by the methods of burning, burying and reverting areas that have finished mineral exploitation in accordance with the law on minerals and other treatment methods according to the relevant specialised laws. In case of the ordinary industrial solid waste is not classified, it must be treated by incineration and burying.

- For hazardous industrial solid waste, the owner of the hazardous industrial solid waste must be responsible for registering the owner of the hazardous solid waste source with the local Department of Natural Resources and Environment at the same place generating the hazardous waste. The owner of the hazardous solid waste must take measures to minimise the generation of the hazardous waste; take responsibility for the discernment, classification and determination of hazardous waste quantities, and must be reported and managed. The owner must has a temporary storage area for the hazardous waste; the store hazardous waste in packages or storage devices that meets the technical requirements and management processes prescribed by Vietnamese law. In case of the owners does not reuse, recycling, co-treatment, treatment and recovery of energy from hazardous waste at their facilities, the owners of hazardous waste must sign a contract with organisations or individuals that have appropriate licenses to transfer. In addition, the hazardous waste owner is responsible for reporting every six months on the storage of the hazardous waste at the facility with the Department of Natural Resources and Environment in a separate paper or combined in the periodically report of hazardous waste management if the hazardous waste has not transferred in the following cases: i) There has been no feasible transportation and treatment plan; ii) There has not found a suitable hazardous waste disposal facility.

Currently, in the Law on Environmental Protection 2014 and the Document consolidating decrees on waste and scrap management of the Ministry of Natural Resources and Environment issued in 2019, there are regulations on reducing, reusing, and recycling waste in waste management and specifying that waste can be reused, recycled and recovered energy must be classified. However, the responsibility to classify waste has not yet been specified for whom. It is the responsibility of the owner of the waste source, the owner of transport and waste disposal or the responsibility of state agencies.

Secondly, the responsibilities of the waste source owner in self-reusing, recycling, treating, co-treating and recovering energy from industrial wastes:

- According to the Clause 4, Article 30 of the Document consolidating decrees on waste and scrap management of the Ministry of Natural Resources and Environment issued in 2019 , the ordinary solid waste owners may reuse, pre-process and recycle, treating, cotreating, recovering energy themselves from ordinary industrial solid waste without having to transfer the industrial solid waste to others, but having to meet the technical requirements and the management processes according to the following requirements: i) Conformity with the certificate of enterprise registration, business registration or investment certificate, investment registration document and other equivalent documents as prescribed by law; ii) Implementation by technology, environmental protected constructions, available equipment of production on the premises of ordinary industrial solid waste generation facilities and 
must ensure the requirements of environmental protection as prescribed. For the solid waste incinerators and the ordinary industrial solid waste burial sites, investments in the premises for self-treatment of common industrial solid waste must be consistent with the contents of solid waste management in the related plan; iii) Must be in accordance with the decision on approval of environmental impact assessment report, certified environmental protection plan or equivalent documents.

Currently, according to the Clause 10, Article 9 of the Document consolidating decrees on waste and scrap management of the Ministry of Natural Resources and Environment issued in 2019, the hazardous industrial solid waste owner may reuse, recycling, cotreatment, treatment and recovery of energy themselves from the hazardous industrial solid waste generated internally within the facility; however, because of no guidance on environmental protection in this regard, this causes confusion during the implementation.

Thirdly, the responsibility of the owner of the solid waste in transferring the industrial solid waste to the transferee:

- Vietnamese law prescribes the responsibilities of the subjects of gathering, transporting and transiting the ordinary industrial solid wastes, ensuring that they must not drop, cause dust, odor or water leakage and meet the technical requirements and management processes according to regulations. In fact, there are many owners of the industrial solid waste sources that do not have the capacity to reuse, pre-process, recycle, treat and recover energy from ordinary industrial solid waste. They have to transfer the industrial solid waste to another entity. However, the law also binds the responsibilities of the industrial solid waste owners to find the entities for the transfer of the industrial solid wastes, namely: i) The owner of production facilities directly use the waste as production materials, construction materials or leveling materials permitted in accordance with law; ii) The owner of the production facility are approved by the competent agency to handle the co-treatment of waste; iii) The owner of the ordinary industrial solid waste treatment have appropriate functions.

The transfer of ordinary solid waste between the owner and the transferee must have a record of handover of the ordinary industrial solid waste for each time. The form of handover record is prescribed by law.

- For the hazardous industrial solid waste owners that cannot reuse, recycle, co-treat, treat or recover energy themselves from the hazardous wastes at their production facilities, the hazardous waste owners must sign contracts to transfer the hazardous waste to organisations and individuals licensed to handle the hazardous industrial solid waste. If it has not been delivered because there is no feasible transporting or handling plan, the hazardous waste owners must report to the Department of Natural Resources and Environment for coordinating to find solutions.

Fourthly, the responsibility of the owner of the waste source must report the situation of the industrial solid waste management:

Reporting on the situation of industrial solid waste management to the management agencies and publishing for people to carry out the supervision, sharing the responsibility of the community are necessary issues in waste management. Currently, according to the provisions of Vietnamese law, it has raised the issue of responsibility for reporting situation of the waste management to state management agencies, specifically:

- For the ordinary industrial solid waste owners, annual reports must be sent to the Department of Natural Resources and Environment on the situation of the ordinary industrial solid waste management, in addition, they must be responsible for unscheduled reporting as the request of state authorities (Source: Article 30, the Document consolidating decrees on waste and scrap management)

- Due to the specific characteristics of the hazardous industrial solid waste, the waste owners must be responsible for reporting every six months on the hazardous waste storage 
at their facilities to the Department of Natural Resources and Environment by paper. The owner of the waste source must prepare, use, store and manage the hazardous waste documents, reports on the hazardous waste management (periodic and unscheduled) and related documents to the hazardous waste management. The termination of activities generating the hazardous waste must be notified in writing to the Department of Natural Resources and Environment where the hazardous waste generating facilities are located within six months.

\subsection{Practical application of laws and some solutions to enhance the responsibility of waste source owners in the management of industrial solid waste in Vietnam}

It can be said that the current situation of the industrial solid waste management in Vietnam has made many advances, methods of managing and solving problems of the industrial solid wastes which have changed from passive responses to proactively control and prevent high risk projects causing environmental pollution toward the sustainable development. The law on the responsibilities of the waste source owners is increasingly improved, showing clearly the waste source owners what to do, must do, and be done with good results. If the results are not good, they will suffer adverse consequences. This ensures the unification of rights and obligations of the waste source owners, helps them to implement actively their responsibilities for the management of the industrial solid waste and assists the state agencies, communities, individuals and organisations in society supervising and supporting the waste source owners to perform their responsibilities better. However, the practice of implementing regulations on the responsibilities of the waste source owners in industrial solid waste management has had some limitations and inadequacies that need to be improved, including:

Firstly, there should be more specific provisions on the responsibilities of the waste source owners in the classification of the industrial solid wastes: The wastes have been discerned and classified as raw materials, fuels and materials for other manufacturing industries in order to promote a circulating economy, recycle and reuse waste. The classification of the industrial solid waste at its source is an effective solution both economically and environmentally. However, the current law only regulates the general requirement to classify the solid waste at source, does not specify clearly who is responsible for classifying, and does not bind the responsibilities of any stakeholder in the management process of the industrial solid waste at source. Therefore, the classification of the industrial solid waste at source will be more practical when it is clearly stated the responsibility of classification. At first is the responsibility of the waste source owner, then, the responsibility of the stakeholders involved in the waste management cycle.

Secondly, it is necessary to supplement and complete the regulations on the market for exchanging the industrial solid waste. Practice shows that the industrial solid waste of a production facility can become a source of raw materials for other production facilities. Thus, the exchange of waste between business groups not only saves production costs, but also has great value in preventing environmental pollution or over-exploitation of natural resources. The current regulation on exchanging the industrial solid waste is only at the recommended level of the law, there is no specific regulation [11]. Therefore, it is necessary to add specific regulations on the exchange of the industrial solid wastes to the current waste management legislation, with specific provisions on the subjects involved in the exchange, the rights and obligations of the exchanging parties, the order of exchange procedures and the State should have mechanisms and policies to encourage the exchange of the industrial solid waste between the owners and the exchanging parties in order to 
create a legal basis for exchange activities of waste between production facilities. Thus, it makes better use of the economic and environmental values of this activity.

Thirdly, to ensure effective performance of the responsibilities of the industrial solid waste owners, it is necessary to supplement the provisions on personnel specialised in performing the industrial solid waste management at establishments generating industrial solid wastes. Because the industrial solid waste management is a professional activity, it requires staffs at facilities generating waste to be trained professionally. However, at present, this is a problem that is underestimated, especially in small and medium enterprises, so the effectiveness of the industrial solid waste management is not high. The implementation of the responsibilities of the solid waste owners is sometimes countermeasures with management agencies. Therefore, it is necessary to supplement the regulations on the compulsory person responsible for pollution control at the production and business establishments. That person must be trained professionally on the environmental pollution control in general and the industrial solid waste management in particular. At that time, the owner of the industrial solid waste will be able to detect the environmental uncertainties early in the enterprise before it happens, ensuring the proactive of enterprises in preventing environmental pollution. For small and medium-sized enterprises, with a small amount of waste discharged into the environment, the waste management professional staffs should be trained and certified in the solid waste management, which demonstrates the responsibility of the business to society. For facilities with large amounts of waste discharged into the environment, seriously affecting the environment, the higher requirements on personnel specialised in the industrial solid waste management may be prescribed [11].

Fourth, strengthen inspection, supervision and implementation of sanctions to improve the responsibilities of industrial solid waste owners.

Current laws provide specific regulations on the responsibilities of the owners of waste sources in the environmental protection in general and the industrial solid waste management in particular. However, the reality shows that, for many reasons including personal interests, many owners of the industrial solid wastes are violating the law on the waste management, discharging waste into the environment; the handling responsibilities of these waste source owners has not been thorough. Although, Decree No. 155/2016/ND-CP on penalties for administrative violations against regulations on environmental protection stipulates groups of violations on the industrial solid waste management are quite extensive, such as: Discharge exceed the Vietnamese standards; violating ordinary the industrial solid waste treatment; violations of the hazardous waste management. However, the current provisions of Decree No. 155/2016/ND-CP on penalties for administrative violations against regulations on environmental protection still reveal limitations such as: Lack of regulations for the behaviour of "waste source owner does not periodically report to the local Department of Natural Resources and Environment on the storage of hazardous waste at the generating facility"; Lack of penalties for collecting, transporting, burying, treating wastes of construction activities [5]. It is necessary to supplement regulations on administrative violations of this group to enhance the responsibilities of violating subjects. Moreover, it is necessary to strengthen inspection, examination and supervision on the waste source owners performing their responsibilities in the industrial solid waste management, and needs to strengthen sanctions to increase the liability for the violating subjects.

Fifthly, it is necessary to complete the legislation on the system of economic intrusments to regulate acts of the waste source owners in the industrial solid waste management.

The economic instruments used in the environmental protection will affect the costs and benefits of businesses, create impacts on the behaviour of the manufacturer on the 
environment, encourage research, deploy techniques and technologies to benefit the environment, increase income sources for the environmental protection. This is also the institutionalisation of the principle: "people who pollute the environment must pay" and "people who benefit from the value of the environment must pay"; hence, it can adjust the behaviour of the manufacturers and consumers. In Vietnam, the question is how to apply market principles and mechanisms to the environmental protection in general and the industrial solid waste management in particular, contributing to create motivation for the parties to change behaviours. Inadequacies in the economic instruments for the environmental protection in Vietnam today are environmental taxes, fees or other forms of environmental rehabilitation deposits that have not been fully and unrealised to mobilise sufficient resources to investment back to the environmental protection. Therefore, the improvement of legislation on the system of the economic instruments and the market mechanism for industrial solid waste management in Vietnam contributes to the owners of the waste sources in recognising their responsibilities and adjusting behaviours in the industrial solid waste management.

Sixthly, it is necessary to mobilise community responsibilities to participate in management and promote socialisation in the industrial solid waste management.

First of all, it is necessary to define clearly the responsibilities of the subjects in the process of the industrial solid waste management. It can be said that the responsibility of the industrial solid waste management belongs to the State, the waste source owners, organisations, individuals and the communities. Because solid waste is discharged to the environment that is likely to cause the environmental pollution, thus, in principle all subjects are obliged to protect the environment. With the role and position of the State in social organisations in general and the environmental management in particular, the State must take the leading responsibility in the environmental protection. Besides the State, the waste source owners play a very important role in the management of industrial solid waste, because waste generated by these subjects contains environmental pollutants. Current laws provide specific provisions on the responsibilities of the owners of the waste sources in the environmental protection. However, the reality shows that, for many reasons, including private interests, many waste source owners are willing to violate environmental laws. In particular, the handling of responsibilities of these owners has not been thorough. In the context of the state agencies and the waste source owners have not properly and effectively performed their responsibilities, the current role of individuals and communities is not worthy of their role in protecting the environment. Therefore, the law on waste management needs to enhance the role of social organisations and communities in monitoring and criticising waste management policies and laws; preventing, detecting, and treating the environmental pollution; initiating lawsuits and claiming environmental damage [6].

Furthermore, it is necessary to promote socialisation in the industrial solid waste management, creating a synchronous mechanism on the responsibilities of each subject including the State, the waste generating enterprises, individuals and other organisations and communities in the cycle of the industrial solid waste management with the goal of reducing, reusing, recycling waste, producing cleaner, sustainable consumption to achieve the goals of developing economy and solving environmental issues more sustainably.

\section{Conclusion}

Based on the research results, some conclusions can be made as follows:

Firstly, as the situation of the industrial solid waste is increasing along with the current industrialisation process in Vietnam, regulations on the responsibilities of the owners of waste sources in the industrial solid waste management play an important role in protecting 
legal rights and interests, as well as binding obligations of the waste source owners. Therefore, the completion of regulations on the responsibilities of the waste source owners contributes to improving the effectiveness of the industrial solid waste management in Vietnam.

Secondly, the regulations on the responsibilities of the waste source owners are gradually improved by the view of the industrial solid waste in Vietnam, which has shifted from the concept of waste to the concept of resource. Therefore, the responsibility of the owner of the industrial solid waste is not only to manage the industrial solid waste not to pollute environment in the waste management cycle, but also responsible for promoting the circulation and recycling and reusing the industrial solid waste in the sense that it is a resource. However, the process of implementing regulations on the responsibilities of the waste source owners still has some limitations and shortcomings that need to be removed to enhance the responsibilities of the industrial solid waste owners.

\section{References}

1. The National Report on Environmental status 2017. Waste management topic (Ministry of Natural Resources and Environment, 2017)

2. Statement of the draft No. 2 on the project amending and supplementing a number of articles of the Law on Environmental Protection (Ministry of Natural Resources and Environment, 2019)

3. Nguyen The Chinh, Vietnam environment administration magazine 10, 29-32 (2019)

4. N. Huy Con, Builders Magazine 12, 26-27 (2008).

5. Le Thi Hang. Vietnam environment administration magazine 9, 47-49 (2019)

6. Bui Duc Hien, Huynh Minh Luan, Vietnam environment administration magazine 11, 29-31 (2019)

7. Tran Linh Huan, Democracy and law magazine 1, 43-48 (2019)

8. Bui Thi Ngoc Mai, Responsibilities of heads of state administrative agencies, Doctoral thesis (2017)

9. Evaluation of domestic solid waste and hazardous waste management (World Bank, Hong Duc Publishing House, 2018)

10. Approving adjustments to the National Strategy on integrated solid waste management up to 2025, vision toward 2050 (Prime Minister, 2018)

11. Vu Thi Duyen Thuy, Vietnam environment administration magazine 2, 9-11 (2020) 